\title{
The preovulatory gonadotrophin-releasing hormone surge: a neuroendocrine signal for ovulation
}

\author{
A. Caraty ${ }^{1}$, N. P. Evans ${ }^{2}$, C. J. Fabre-Nys ${ }^{1}$ and F. J. Karsch ${ }^{2}$ \\ ${ }^{7}$ Station de Physiologie de la Reproduction des Mammifères Domestiques, INRA 37380, Nouzilly, \\ France, ${ }^{2}$ Reproductive Sciences Program and Department of Physiology, University of Michigan, \\ Ann Arbor, MI, USA
}

\begin{abstract}
Recent studies have demonstrated that an important component of the positive feedback response to oestradiol in mammals is an action within the central nervous system to induce a large surge in the secretion of gonadotrophin-releasing hormone $(\mathrm{GnRH})$. This oestradiol-induced neuroendocrine signal for ovulation has been best characterized in ewes. The GnRH surge is high in amplitude; the amount secreted increases on average more than 40 times above the pre-surge baseline value. The initial increment in GnRH secretion precedes or coincides with the onset of the LH surge. The GnRH surge is of extended duration, lasting far longer than the preovulatory $\mathrm{LH}$ surge. A molecular variant of $\mathrm{GnRH}$, which is less active biologically than native $\mathrm{GnRH}$, is co-secreted at the time of the surge, but termination of the LH surge cannot be accounted for by a change in biological activity of the secreted GnRH. Generation of the GnRH surge appears to follow a characteristic progressive change in the pattern of $\mathrm{GnRH}$ in portal blood. High concentrations of oestradiol initially stimulate the secretion of $\mathrm{GnRH}$ between pulses; this is followed by augmentation of both pulsatile and interpulse $\mathrm{GnRH}$ release producing the rising limb of the surge. Finally, recent experiments have indicated that the local application of oestradiol to the ventromedial nucleus of the hypothalamus is sufficient to stimulate the GnRH surge, suggesting a key role for this hypothalamic area in the generation of this neuroendocrine signal for ovulation.
\end{abstract}

\section{Introduction}

The preovulatory surge of gonadotrophic hormones from the anterior pituitary gland is the regulatory pivotal step in the oestrous and menstrual cycle because it induces ovulation. A great deal of effort has been spent to gain an understanding of the factors that regulate the occurrence of the preovulatory gonadotrophin surge. It has long been known that an increase in ovarian oestradiol secretion is required for induction of the preovulatory surges of LH and FSH. In many species including rats (Aiyer et al., 1974), sheep (Reeves et al. 1971) and monkeys (Knobil, 1974), it has been demonstrated that oestradiol increases the pituitary responsiveness to GnRH. However, it has become evident that another important component of the positive feedback response to oestradiol is an action within the central nervous system to induce marked changes in the secretion of GnRH. Historically, this neural component of the positive feedback response has been difficult to characterize owing to the nature of the GnRH neuronal system itself. In this regard, there are only a few thousand $\mathrm{GnRH}$ neurones; they are widely dispersed throughout the hypothalamus; and not all of them are in contact with the portal vessels of the median eminence (Silverman et al, 1990). Even in hypophyseal portal blood, where the neurosecretory signal is concentrated, the amount of $\mathrm{GnRH}$ is relatively small. 
The development of various methods for measurement of $\mathrm{GnRH}$ secretion has led to the demonstration that there is an unambiguous and sustained surge of GnRH at the time of the preovulatory LH surge in rats (Sarkar et al., 1976; Ching, 1982), ewes (Domanski et al., 1991; Moenter ef al, 1991), monkeys (Xia et al., 1992; Pau et al, 1993) and mares (Irvine and Alexander, 1994). In most of these species, it has also been confirmed that the preovulatory increase in oestradiol plays an essential role in triggering a cascade of neuroendocrine events that culminate in the GnRH surge (Sarkar and Fink, 1979; Clarke, 1988; Caraty et al., 1989; Moenter et al., 1990; Xia et al., 1992). In this report, we summarize these findings and those of subsequent experiments to examine the mechanisms responsible for generation of this neuroendocrine signal for ovulation in ewes.

\section{The Preovulatory GnRH Surge}

The first evidence for increased GnRH release into hypophyseal portal blood at the time of the LH surge was obtained in anaesthetized laboratory rats (Sarkar et al., 1976). This observation was facilitated by the availability of a technique for sampling hypophyseal portal blood and the fact that the gonadotrophin surge in this species is precisely timed on the day of pro-oestrus. This result (illustrated in Fig. 1a) was later confirmed by Ching (1982). However, progress in this area in other species was hindered by the lack of reliable techniques for monitoring the pattern of hypothalamic substances, such as $\mathrm{GnRH}$, in hypophyseal portal blood. In 1982, a method for obtaining sequential samples of hypophyseal portal blood from conscious undisturbed sheep was developed by Clarke and Cummins (1982). However, the initial report of the pattern of GnRH secretion at the time of the preovulatory $\mathrm{LH}$ surge in ewes did not substantiate the view that an increase in $\mathrm{GnRH}$ secretion was an important stimulus for generation of the gonadotrophin surge. Notably, the pattern of GnRH release was found to be highly variable and did not necessarily undergo a noticeable change during the LH surge (Clarke et al., 1987). This finding was more in keeping with the view that the anterior pituitary gland was the primary site for the positive feedback action of oestradiol in sheep, as had been proposed for rhesus monkeys (Knobil et al., 1980).

We were uncomfortable with the inconsistent patterns of $\mathrm{GnRH}$ release during the $\mathrm{LH}$ surge in ewes, because indirect evidence had been compiled to suggest that, unlike in monkeys, generation of the preovulatory $\mathrm{LH}$ surge in ewes requires a large increase in GnRH release (Kaynard et al., 1988). Subsequently, we developed a modified approach for the collection of hypophyseal portal blood that allowed sampling from the same animal for up to 48 consecutive hours (Caraty and Locatelli, 1988). This period was sufficient to span not only the LH surge but also the pre-surge period. We then used this technique to assess the role and importance of changes in $\mathrm{GnRH}$ secretion to the generation of the preovulatory sequence of events in ewes.

In our initial studies, portal and jugular blood were collected at intervals of $10 \mathrm{~min}$ for $24-48 \mathrm{~h}$ across the period leading up to and during the expected time of the preovulatory LH surge in intact cyclic ewes (Moenter et al., 1991). Owing to the difficulty in accurately predicting the time of onset of the LH surge in intact animals, it was necessary to use a large number of sheep. This experiment, was therefore conducted over two years in our laboratories in France and Michigan, and included two breeds of sheep, Ile de France and Suffolk. In each of 11 ewes in which portal blood was sampled during all or part of the $\mathrm{LH}$ surge, we obtained evidence for an unambiguous increase of $\mathrm{GnRH}$ release. An example of the dynamics of GnRH and LH release over 48 continuous hours leading to ovulation in one ewe is shown (Fig. 1b). Several points are of particular interest. As the follicular phase progressed and oestradiol secretion increased, there was initially a reduction in $\mathrm{GnRH}$ pulse amplitude and often an increase in pulse frequency. A robust GnRH surge then occurred coincident with the onset of the preovulatory LH surge. During this surge, a strictly pulsatile pattern of secretion was not clearly evident as GnRH values remained continuously high. Our finding and those from a study using push-pull perfusion of the median eminence (Domanski ef al, 1991) provide definitive evidence for the existence of a preovulatory GnRH surge in ewes.

Finally, recent reports in monkeys (Xia ef al,, 1992, Pau et al., 1993) and mares (Irvine and Alexander, 1994) involving various methods have provided evidence for the existence of an unambiguous $\mathrm{GnRH}$ surge at the time of the LH surge in these species. A representative example of the pattern of GnRH and 

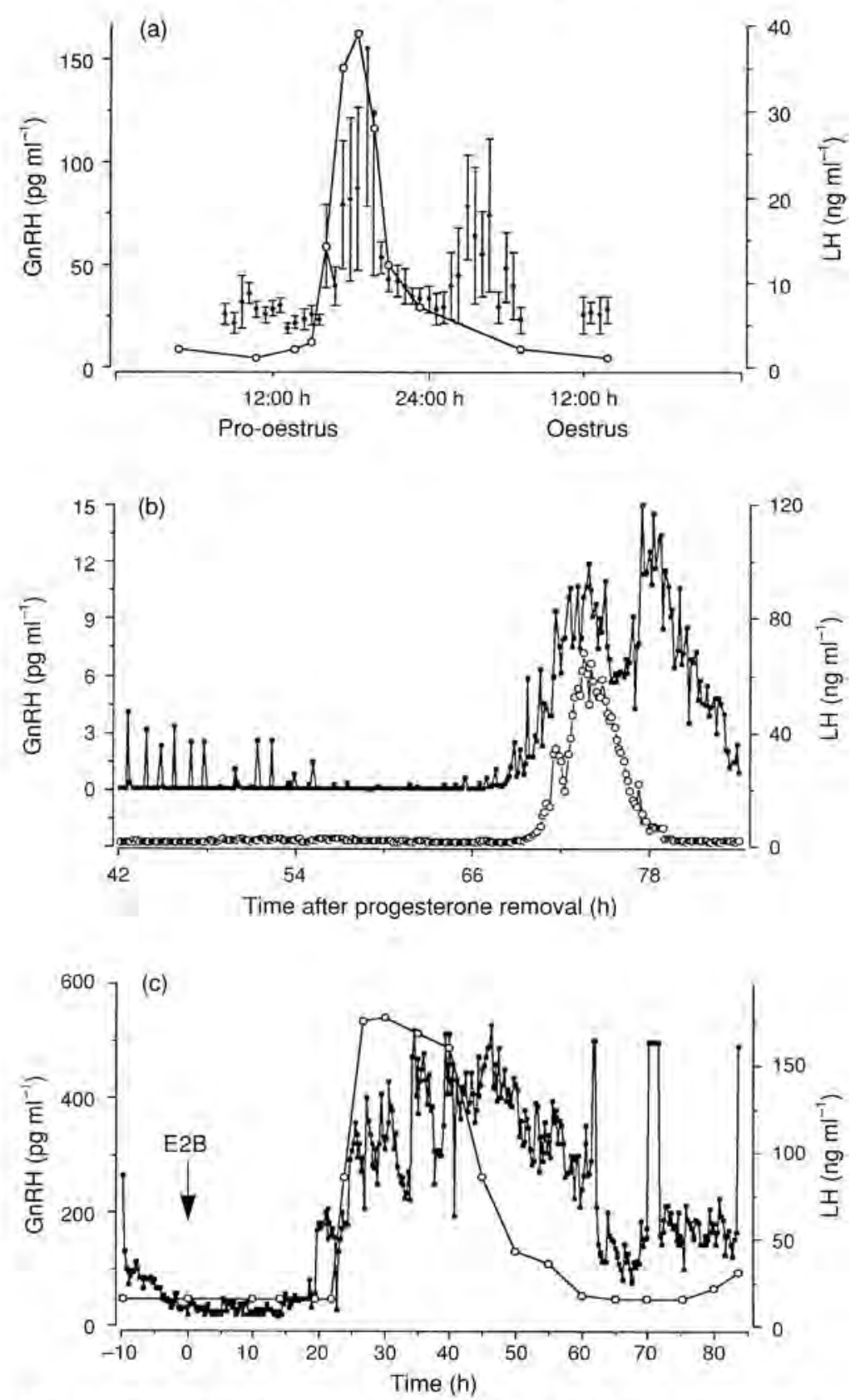

Fig. 1. Comparative patterns of GnRH secretion (., .) and LH secretion () (a) during the day of pro-oestrus and oestrus in rats (redrawn from Sarkar et al, 1976), (b) during the late follicular phase of the oestrous cycle in a representative ewe (redrawn from Moenter et al., 1991) and (c) after administration of oestradiol benzoate (E2B) in intact monkeys (redrawn from Xia et al., 1992).

$\mathrm{LH}$ released in response to oestradiol benzoate administration in an intact monkey is shown (Fig. 1c). Certain characteristics of the GnRH surges observed in these three species are similar. In each case, the amplitude of the GnRH surge is large and the surge lasted far longer than the preovulatory LH surge. 
This latter observation indicates that the end of the $\mathrm{LH}$ surge is not due to lack of $\mathrm{GnRH}$, and this point is considered in greater detail later. As the GnRH surge appears to be a common neuroendocrine signal for ovulation in many species, it is important to consider the mechanisms that lead to its generation.

\section{Role of Oestradiol in the Induction of the GnRH Surge}

In ovariectomized ewes, it has been widely shown that oestradiol inhibits LH secretion before inducing a large release of LH that is similar to the spontaneous preovulatory LH surge (Pelletier and Signoret, 1969). However, the first studies to describe the effects of large doses of oestradiol on $\mathrm{GnRH}$ secretion did not provide definitive results, as the patterns of $\mathrm{GnRH}$ secretion obtained were not consistent among animals (Clarke and Cummins, 1985; Schillo et al., 1985). We therefore used the technique developed for the collection of hypophyseal portal blood to study the pattern of GnRH secretion following intravenous injection of a bolus of oestrogen to ovariectomized ewes during the breeding season (Caraty et al., 1989). Oestradiol induced the expected biphasic pattern of LH release in the peripheral circulation, an initial decrease (negative feedback) followed by an increase (positive feedback). Of greater interest, a similar biphasic pattern was also observed for GnRH in the hypophyseal portal circulation. During the period of negative feedback of LH secretion, a clear but less marked decrease was observed in both GnRH pulse frequency and amplitude. During the positive feedback phase, a large and unambiguous surge of $\mathrm{GnRH}$ occurred coincident with the LH surge. It was also observed that, much as during the preovulatory GnRH surge, the pattern of $\mathrm{GnRH}$ release changed such that $\mathrm{GnRH}$ was continuously high and discrete pulses were no longer evident.

These results, in conjunction with earlier observations that administration of a bolus of oestradiol to intact anoestrous ewes stimulated a clear increase in GnRH secretion at the time of the LH surge (Clarke, 1988), provide the first direct evidence that an abrupt increase in GnRH secretion is a key component of the positive feedback effects of oestradiol on LH secretion in ewes. However, as the circulating concentration of oestradiol achieved in our first experiment was calculated to be well above the physiological range, we next studied the pattern of $\mathrm{GnRH}$ secretion at the time of the $\mathrm{LH}$ surge in a previously developed physiological experimental model (Goodman, 1988). In this model, the steroidal milieu of the follicular phase of the oestrous cycle is simulated to produce an artificial follicular phase. Separate experiments were conducted during both the breeding and anoestrous seasons.

A representative pattern of $\mathrm{GnRH}$ secretion at the time of an $\mathrm{LH}$ surge induced in the artificial follicular phase model during the breeding season is illustrated in Fig. 2 (Moenter et al., 1990), Before the LH surge, the concentration of GnRH in portal blood was very low owing to the negative feedback effects of the peak follicular phase concentrations of oestradiol. In all animals, this was followed by an unambiguous surge of $\mathrm{GnRH}$ secretion. The absolute requirement of oestradiol for induction of this surge was demonstrated by the absence of an increase in GrRH secretion in control animals that did not receive oestradiol. The induced $\mathrm{GnRH}$ surge was essentially indistinguishable from the spontaneous preovulatory GnRH surge. It invariably began coincident with the LH surge but continued well beyond the LH surge, again providing evidence that the LH surge is terminated for reasons other than a lack of $\mathrm{GnRH}$. The induced surge was of high amplitude; peak $\mathrm{GnRH}$ concentrations typically exceeded the pre-surge baseline value by more than 100 times. Finally, we found that the time course and magnitude of the GnRH surges induced in the artificial follicular phase model did not differ between the breeding and anoestrous seasons. The demonstration of consistent unambiguous surges of $\mathrm{GnRH}$ secretion in these studies using a physiological model of the follicular phase provides compelling evidence that the preovulatory rise of oestradiol secretion causes an abrupt and robust activation of the GnRH neurosecretory system, before ovulation, in ewes.

\section{Nature of the GnRH Secreted During the Surge}

As described above, we have consistently observed that the spontaneous and oestradiol-induced GnRH surges continue for many hours beyond the LH surge. One implication of this observation is that the LH surge terminates for reasons other than a lack of $\mathrm{GnRH}$, for example pituitary depletion or 


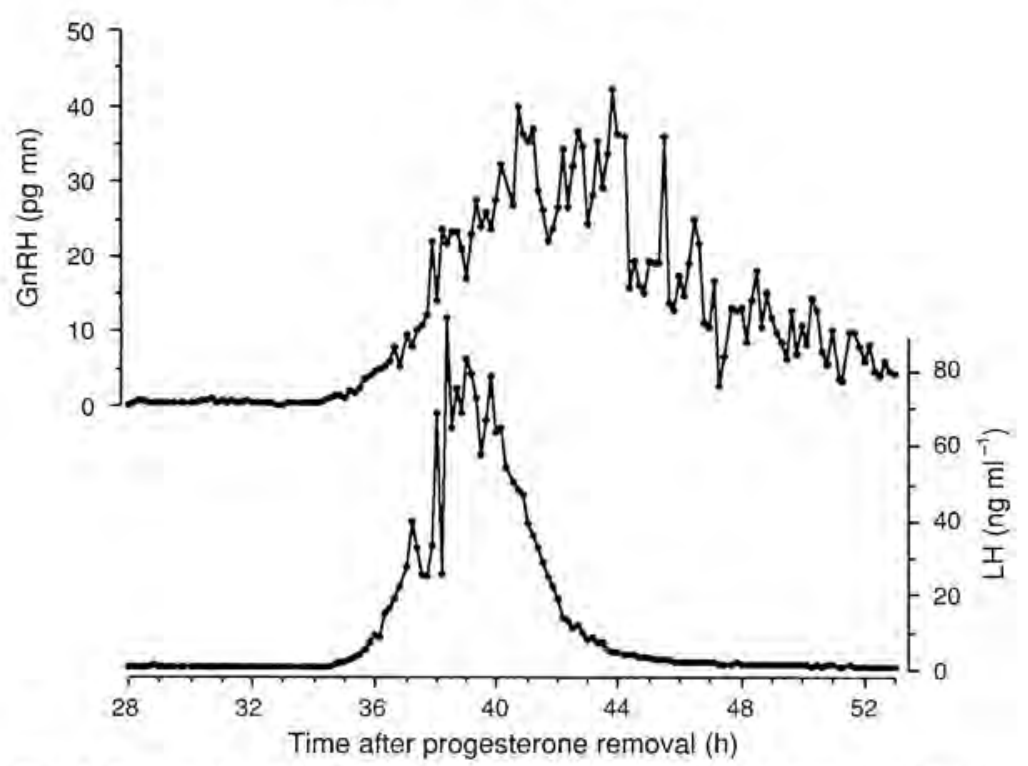

Fig. 2, Pattern of GnRH in hypophyseal portal blood and LH in jugular blood in a representative ewe in the follicular phase model. The oestradiol rise was initiated $16 \mathrm{~h}$ after removal of progesterone. Redrawn from Moenter et al. (1990).

desensitization. However, there is another possibility. Recent studies have demonstrated the presence of at least one other molecular form of $\mathrm{GnRH}$, hydroxyproline-9-GnRH (Hyp-GnRH), in the hypothalami of a variety of vertebrates including rats, mice, frogs, humans and sheep (Gautron et al, 1991). Moreover. Hyp-GnRH is less potent than native $\mathrm{GnRH}$ in stimulating the release of LH and FSH from the pituitary (Gautron et al, 1992). Thus, termination of the LH surge might be due to a change in the form of secreted GnRH from the native decapeptide to a less biologically active molecule such as Hyp-GnRH. It should be noted, with regard to this explanation, that GnRH surges sometimes exhibit a biphasic profile (Fig. Ib), suggesting possible successive release of two forms of $\mathrm{GnRH}$. In an attempt to resolve this issue and to study the nature of $\mathrm{GnRH}$ secreted during the surge, we conducted the three experiments summarized below.

In the first experiment, $\mathrm{GnRH}$ immunoreactivity was determined in hypophyseal portal blood during an oestradiol-induced GnRH surge using two different antibodies having respective specificity toward the amino- and carboxyl-terminal portions of the GnRH molecule (Caraty et al., 1993). Binding to the first antibody (BDS antibody) was found to require the first seven amino acids of the GnRH molecule and, therefore, the antibody recognizes both native $\mathrm{GnRH}$ and molecules having modifications in the carboxyl-terminal portion of the molecule (for example Hyp-GnRH). However, binding to the second antibody (CRR antibody) requires the last five amino acids of the GnRH molecule. This antibody, therefore, does not bind carboxy-terminal modifications of the native GnRH decapeptide (that is, does not bind Hyp-GnRH). These antibodies were used to study the patterns of immunoreactivity in samples of hypophyseal portal blood collected during oestradiol-induced GnRH surges. Patterns of GnRH immunoreactivity measured with each of these antibodies from the same samples of hypophyseal portal blood of one representative animal are illustrated (Fig. 3). For all animals $(n=8)$, there was no significant difference in either the pattern, quantity, time of onset, or duration of $\mathrm{GnRH}$ secreted during the surge. Owing to the specificity of the antibodies, this experiment provides evidence that GnRH released during the surge is mainly of one form, the native GnRH.

In the second experiment, we tested whether the GnRH molecules released during the latter part of the GnRH surge are biologically active. Our approach was to block the ability of the pituitary to respond to $\mathrm{GnRH}$ for several hours at the beginning of the surge by administration of a GnRH antagonist. If the $\mathrm{GnRH}$ released during the latter part of the surge is biologically active, then an 


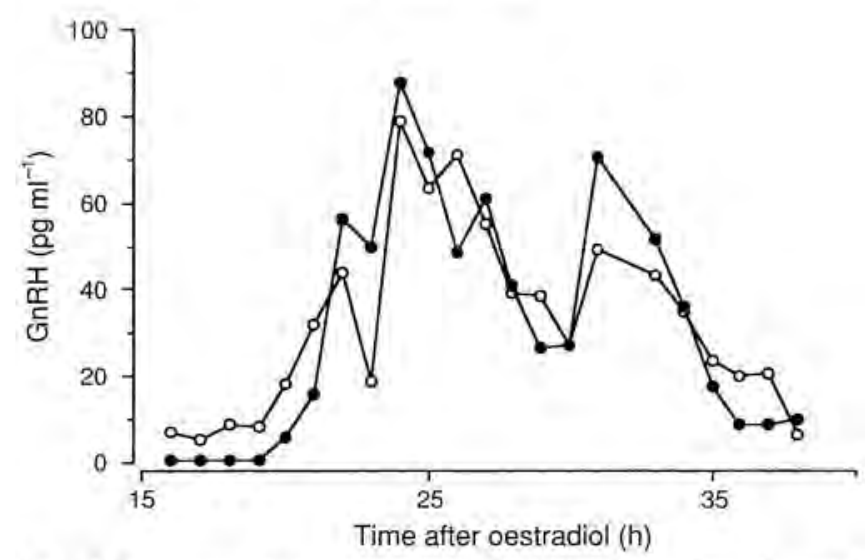

Fig. 3. Immunoreactive patterns of GnRH in hypophyseal portal blood measured with an antibody specific for the amino-terminal portion $(\bullet)$ or the carboxy-terminal portion ( 0 ) of the GnRH molecule throughout a $\mathrm{GnRH}$ surge induced in the follicular phase model. Redrawn from Caraty et al. (1992).

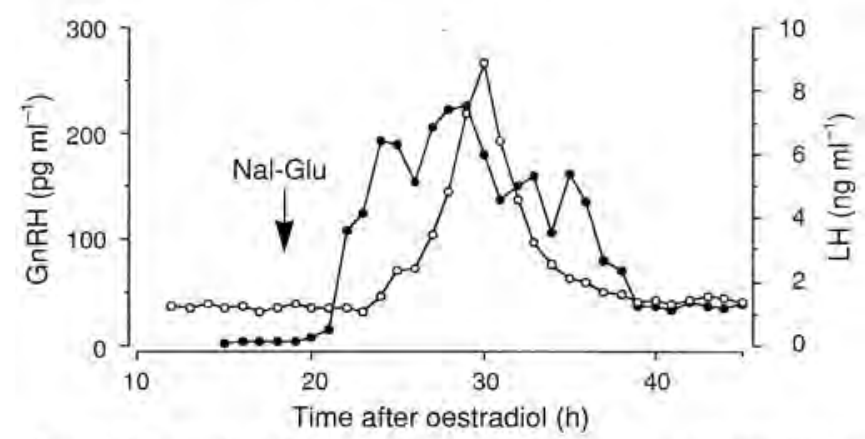

Fig. 4. Pattern of GnRH in hypophyseal portal blood $(\bullet)$ and LH in jugular blood () throughout an oestradiol-induced GnRH surge of a representative ewe. Time of administration of the $\mathrm{GnRH}$ antagonist (Nal-Glu) is indicated by the arrow. Redrawn from Caraty of al. (1992).

increase in LH would be expected to occur once the effect of the antagonist had worn off (that is, during the latter part of the GnRH surge). Ewes set up in the follicular phase model were treated with the antagonist Nal-Glu, 2-3 h before the expected onset of the LH and GnRH surges. (Nal-Glu binds competitively to the GnRH receptor.) The dose of Nal-Glu used was determined in pilot experiments to block pituitary responsiveness to $\mathrm{GnRH}$ for $6-10 \mathrm{~h}$. As expected with the follicular phase model, a surge of $\mathrm{GnRH}$ began about $20 \mathrm{~h}$ after administration of oestradiol but an LH surge did not begin at that time, owing to the action of Nal-Glu. Of interest, a marked increase in LH did begin about $5 \mathrm{~h}$ later (Fig. 4). (The magnitude of the LH increase was less than that of LH surges shown in Figs $I$ and 2 , but this is due in part to different assay standards used in France and Michigan.) This $\mathrm{LH}$ response during the latter part of the $\mathrm{GnRH}$ surge, in conjunction with recent findings that the $\mathrm{GnRH}$ present in portal blood obtained late in the surge can stimulate gonadotrophin secretion in vitro (Padmanabhan et al., 1994) demonstrates that at least some of the $\mathrm{GnRH}$ molecules released at the end of the surge are biologically active. Together with the results of the first experiment, this indicates that a change in the form of the GnRH from the native peptide to a less active molecule is not the reason for termination of the $\mathrm{LH}$ surge. 
To determine whether any other GnRH forms are secreted in hypophyseal portal blood during the surge, we conducted a third experiment (Delaleu et al., 1993). Pools of hypophyseal portal blood corresponding to the first and second halves of the oestradiol-induced GnRH surges were submitted to purification on a reverse phase HPLC column as described by Gautron et al. (1991). The elution fractions were then assayed using the two antibodies having specificity against the amino- and carboxyl-portions of the GnRH molecule described above. During both the first and second halves of the surge, most of the GnRH molecules behaved immunologically and biochemically as the native decapeptide. A small proportion of a second form of GnRH was also observed; it had an elution pattern identical to that of Hyp-GnRH and was not recognized by the antibody specific to the carboxyl-terminal portion of the GnRH molecule. However this modified form of the GnRH molecule represented only $16.7 \pm 3.3 \%$ $(n=5)$ of the total immunoreactivity and did not change between the first and second halves of the GnRH surge.

Collectively, the results of these three experiments indicate that one major form of GnRH is secreted during the entire surge and that this form is the biologically active decapeptide. Thus, termination of the LH surge before the end of the GnRH surge must be due to reasons other than a lack of biologically active GnRH. These could include exhaustion of the releasable pool of LH in the pituitary (Crowder and Nett, 1984) or pituitary desensitization (Nett et al., I981).

\section{Mode of Activation of the GnRH Neurosecretory System}

The magnitude of the $\mathrm{GnRH}$ surge raises intriguing questions related to both the GnRH neurosecretory process and the mode of action of oestradiol. For example, does oestradiol induce the GnRH surge by accelerating or heightening the episodic pattern of release? Alternatively, does oestradiol elicit the surge by causing a switch from a pattern of secretion that is strictly pulsatile to a pattern that produces a continuous release of $\mathrm{GnRH}$ in portal blood.

Studies with ewes (Clarke and Cummins, 1985; Caraty et al., 1989) led to the conclusion that, during the oestradiol-induced LH surge, there is an increase in $\mathrm{GnRH}$ pulse frequency as well as an increase in the basal concentration of GnRH. However, the relatively long interval between blood samples $(5-10 \mathrm{~min})$ in those studies precluded accurate characterization of the dynamics of $\mathrm{GnRH}$ release at the time of the surge. The moment to moment pattern of secretion during the GnRH surge was later re-examined by Moenter et al. (1992a) using more frequent sampling. By taking portal samples every $30 \mathrm{~s}$, it was first demonstrated that in ovariectomized ewes, GnRH secretion is strictly pulsatile (Moenter et al, 1992b). In this situation, the dynamics of a GnRH pulse resembled a square wave, consisting of 5-8 min of high secretion followed by between pulse periods when there is little or no detectable GnRH release. However, during the surge, the pattern was markedly different. Despite considerable fluctuations between contiguous points suggesting a variable rate of release, $\mathrm{GnRH}$ values remained continuously high with no consistent evidence for a period without release. Although a component of episodic release cannot be totally eliminated on the basis of that study, it was suggested that an element of continuous GnRH release occurs during the surge. This led to the hypothesis that oestradiol may induce the GnRH surge by causing a switch from a strictly pulsatile pattern of secretion to a pattern that leads to an uninterrupted discharge of decapeptide.

As an initial test of this hypothesis, very frequent samples of pituitary portal blood were collected from ovariectomized ewes exposed to different oestradiol concentrations, to determine whether oestradiol induces qualitative changes in the pattern of $\mathrm{GnRH}$ secretion (Evans et al, 1993a). It was observed that, although $\mathrm{GnRH}$ patterns were strictly pulsatile in ovariectomized ewes, treatment with increasing concentrations of oestradiol stimulated the release of significant amounts of $\mathrm{GnRH}$ between pulses. Thus, we postulated that the preovulatory rise in oestradiol enhances the release of GnRH between pulses, leading to continuously high secretion during the preovulatory GnRH surge. In another experiment, the moment to moment changes in GnRH secretion during the onset of the GnRH surge were examined, to trace the development of the interpulse $\mathrm{GnRH}$ release and thereby gain additional insight into its contribution to the generation of the surge (Evans et al., 1993b). The follicular phase model was set up in seven ewes and samples of hypophyseal portal blood collected at intervals of I min 
for $11 \mathrm{~h}$, thus encompassing the onset of the GnRH surge. Preliminary analysis of our findings revealed that a consistent qualitative change in the mode of GnRH secretion occurs at the start of the surge. Initially, GnRH secretion changed from being strictly pulsatile (that is, no detectable GnRH between pulses) to pulsatile in combination with significant interpulse secretion. This was followed by augmentation of both pulsatile and inter-pulse components, before a prolonged period during which GnRH secretion, although greatly increased, was not organized in a pattern of obvious pulses. Onset of the LH surges in this experiment coincided with the emergence of detectable release of $\mathrm{GnRH}$ between pulses. In a similar type of study in which portal blood was sampled at intervals of 2 min, Clarke (1993) observed a highly variable pattern of GnRH secretion among ewes at the start of the surge. This is in marked contrast to the consistent pattern among ewes in our studies described above. This discrepancy may be due to procedural differences in collecting portal blood or to the different animal models used in our respective laboratories (long-term ovariectomized ewes given a bolus injection of oestradiol benzoate in Clarke's studies as opposed to the artificial follicular phase model in our experiments).

Although the reasons for the differences between our findings and those of Clarke (1993) are not known, the results obtained in our laboratory support the hypothesis that oestradiol induces the $\mathrm{GnRH}$ surge by changing the organization of the firing pattern among GnRH neurones from a pattern that is synchronous and causes a strictly pulsatile release to an uninterrupted discharge of GnRH into portal blood. Such changes may reflect one or more of several mechanisms including: progressive desynchronization of GnRH neurones that previously fired in unison; extreme acceleration of frequency of episodic release such that the interval between bursts is less than can be resolved by the sampling system; recruitment of a surge-specific population of GnRH neurones that fire in a non-synchronous fashion. However, the magnitude of the GnRH surge relative to that of the antecedent pulses makes it unlikely that the surge is due simply to desynchronization. In rats, the presence of a surge-specific population of neurones is supported by data showing recruitment of $\mathrm{GnRH}$ neurones expressing c-Fos activity during the ascending phase of the pro-oestrous surge (Lee et al., 1992) and by a regional pattern of periovulatory GnRH gene expression at the time of the surge (Porkka-Heiskanen et al., 1993). In ewes, c-Fos expression also increases during the oestradiol-induced GnRH surge (Moenter et al., 1993), but it is without a specific regional distribution. Among the other possibilities, it should be noted that the episodic pattern of hypothalamic electrical activity associated with pulsatile $\mathrm{LH}$ secretion is not observed during the LH surge in monkeys and rats (O'Byrne et al., 1991; Nishihara et al., 1994) and decreases in goats (Tanaka et al. 1992). These data could be interpreted in two ways. Either the positive feedback effects of oestradiol on $\mathrm{GnRH}$ secretion are exerted through a neuronal mechanism that is intrinsically different from the system responsible for pulsatile release of $\mathrm{GnRH}$, or a desynchronization of the $\mathrm{GnRH}$ neurones during the surge precludes detection of an episodic electrical signal. Clearly, further investigation is necessary to determine the mechanism(s) by which the increment of oestradiol activates the GnRH neuronal system.

\section{Site of Oestradiol in Induction of the GnRH Surge in Ewes}

Given the crucial role of oestradiol in inducing the GnRH surge, another important question emerges. Where in the central nervous system does oestradiol act to stimulate GnRH secretion? Although the answer is not known for ewes, it is pertinent to note that, as in rats (Shivers et al, 1983), GnRH neurones in ewes appear to contain few, if any, receptors for oestradiol (Lehman and Karsch, 1993). Therefore, the effect of oestradiol on the activity of these neurones must be mediated by an oestrogen-sensitive afferent neuronal system. In rats, the rostral medial preoptic area (MPOA) is required for oestrogen-induced LH surges (Petersen et al., 1989). In ewes, placement of oestradiol implants into the ventromedial nucleus of the hypothalamus, but not in the preoptic area, was effective in eliciting both oestrous behaviour and LH release (Blache et al., 1991). On the basis of the latter finding, we recently conducted experiments to determine where in the hypothalamus oestradiol acts to elicit the GnRH surge in ewes.

Sheep were ovariectomized and immediately treated with oestradiol and progesterone to simulate naturally occurring changes in steroid concentrations, thus creating repeated artificial oestrous cycles. In some cycles (positive controls), the oestradiol stimulus for the GnRH surge was provided by 
subcutaneous implants. In other cycles, oestradiol was given using implants placed in the ventromedial nucleus of the hypothalamus. Negative controls received cholesterol implants in the hypothalamus. Hypophyseal portal blood was sampled once an hour to monitor the secretion of $\mathrm{GnRH}$ over about $30 \mathrm{~h}$. Thus far, we have obtained data on five ewes in which oestradiol implanted into the ventromedial nucleus induced a GnRH surge and five others in which hypothalamic implants were ineffective in this regard. We are currently evaluating whether there is a relationship between the effectiveness of the brain implants in inducing the surge and the density of oestradiol receptors in close proximity to the implantation sites. For those ewes that exhibited a GnRH surge, the pattern of the $\mathrm{GnRH}$ response induced by the brain oestradiol implants was similar to that of the positive control ewes treated peripherally with oestradiol. However, the amplitude of the GnRH surges induced by the brain implants appeared to be slightly less than that in the positive controls, suggesting that not all of the stimulatory inputs to the GnRH neuronal network had been activated. None of the negative control animals treated with hypothalamic implants of cholesterol responded with a surge.

These findings provide strong evidence that oestradiol acts, at least in part, in or around the ventromedial nucleus of the hypothalamus to induce the GnRH surge. Moreover, since GnRH surges were induced in only some ewes with implants in this location, the site for the positive feedback action of oestradiol in ewes would appear to be rather confined. Taken together with the fact that oestradiol probably does not diffuse more than one millimetre from the tip of the implant (Blache ef al., 1991), a possible action of oestradiol in more anterior regions of the hypothalamus seems unlikely. This is in contrast to the positive feedback effect of oestrogen in rats which seems to be restricted to the rostral medial preoptic area (Petersen et al., 1989). Our results, however, are consistent with earlier evidence that LH surges can be induced in ewes by oestradiol implants placed in the ventromedial region but not in the preoptic area (Blache et al., 199I), and they suggest that anterior structures do not constitute a main site for the positive feedback action of oestradiol in sheep. In this regard, it is notable that $34 \%$ of the neurones of the medial basal hypothalamus of ewes were found to exhibit increased electrical activity following i.v. injection of oestradiol (Thiery, 1975). Furthermore, a large population of immunoreactive cells containing the oestrogen receptor has been identified in the ventrolateral-ventromedial hypothalamus of ewes (Lehman et al., 1993; Blache et al., 1994), Finally, a change in the density of immunoreactive cells containing oestrogen receptors during the course of the oestrous cycle of ewes has been found in the ventromedial nucleus, but not in other regions of the hypothalamus (Blache et al., 1994). Although our findings do not exclude an action of oestradiol elsewhere in the brain, they provide evidence that the ventromedial nucleus is an important site for the positive feedback effect of oestrogen on GnRH secretion in ewes. Additional studies are now required to describe the anatomical and neurochemical links between neurones in the mediobasal hypothalamus bearing oestradiol receptors and the GnRH neuronal system.

\section{Conclusion}

A large and sustained preovulatory $\mathrm{GnRH}$ surge is an important neuroendocrine signal delivered by the hypothalamus in response to increased ovarian secretion of oestradiol during the follicular phase of the cycle. This neuroendocrine signal, which is massive and sustained, appears to be a common component of the gonadotrophin surge mechanism for many species. In ewes, this surge probably results from an action of oestradiol within, or near, the ventromedial nucleus of the hypothalamus. By acting at this site, oestradiol appears to cause a switch in the mode of GnRH secretion from a strictly episodic to a sustained increase in GnRH in portal blood. Many important questions must still be answered before we fully understand the steps for generation of this neuronal event, which is crucial to ovulation and thus successful reproduction.

Studies in France were supported by a grant from 'La region centre' and studies in USA were supported by grants from NIH (HD-18337, HD-18258, HD-30773) and the USDA (90-37240-5507 and 92-37203-7922). The authors thank F. Thomas (IPSEN/BIOTECH Laboratory), R. Deghenghi (Europeptides, France), and the Rackham School of Graduate Studies at the University of Michigan for travel support. 


\section{References}

Aiyer MS, Fink G and Greig F (1974) Changes in the sensitivity of the pituitary gland to luteinizing hormone releasing factor during the estrous cycle of the rat Joumal of Endocrinology 60 47-64

Blache D, Fabre-Nys CJ and Venier G (1991) Ventromedial hypothalamus as a target for oestradiol action on proceptivity, receptivity and luteinizing hormone surge of the ewe Brain Research $\mathbf{5 4 6}$ 241-249

Blache D, Batailler M and Fabre-Nys CJ (1994) Oestrogen receptors in the preoptico-hypothalamic continuum: immunohistochemical study of the distribution and cell density during induced oestrous cycle in the oyariectomized ewe Joumal of Neuroendocrinology 6 329-339

Caraty A and Locatelli A (1988) Effect of time after castration on secretion of LHRH and LH in the ram joumal of Reproduction and Fertility $\mathbf{8 2} 203-269$

Caraty A, Locatelli A and Martin GB (1989) Biphasic response in the secretion of gonadotrophin-releasing hormone in ovariectomized ewes injected with oestradiol journal of Endocrinology $123 \quad 375-382$

Caraty A, Antoine C, Delaleu B, Locatelli A, Bouchard P, Gautron JP, Evans NP, Moenter SM and Karsch FJ (1992) The preovulatory surge of $\mathrm{GnRH}$ in the ewe, $\mathrm{GnRH}, \mathrm{GnRH}$ analogs, gonadotropins and gonadal peptides pp 11.3-124 Eds P Bouchard. A Caraty. HJT Coelingh Bennink and $S$ Pavlou. The Parthenon Publishing Group, London

Caraty A, Antoine $C_{\text {, }}$ Delaleu B, Locatelli A, Gautron JP and Bouchard P (1993) Nature of GnRH secreted into hypophyseal portal blood during the estrogen induced GnRH surge in the ewe The Endocrine Society 75th Amual Meeting, Abstract 1812

Ching M (1982) Correlative surges of LHRH, LH and FSH in pituitary stalk plasma and systemic plasma of rat during procstrus Neuroendocrinology $34 \quad 279-285$

Clarke IJ (1988) Gonadotrophin-releasing hormone secretion $(\mathrm{GnRH})$ in anoestrous ewes and the induction of GnRH surges by oestrogen Journal of Endocrinology $117355-360$

Clarke II (1993) Variable patterns of gonadotropin-releasing hormone secretion during the estrogen-induced luteinizing hormone surge in ovariectomized ewes Endocrinology 133 1624-1632

Clarke IJ and Cummins JT (1982) The temporal relationship between gonadotropin-releasing hormone $(\mathrm{GnRH})$ and luteinizing hormone (LH) in ovariectomized ewes Endocrinology 111 1737-1739

Clarke IJ and Cummins IT (1985) Increased gonadotropinreleasing hormone pulse frequency associated with estrogen-induced luteinizing hormone surges in ovariectomized ewes Endocrinology $1162370^{\circ}-2383$

Clarke IJ. Thomas GB, Yao B and Cummins JT (1987) GnRH secretion throughout the ovine estrous cycle Neuroendocrinology $46 \quad 82-88$

Crowder ME and Nett TM (1984) Pituitary content of gonadotropins and receptors for gonadotropin-releasing hormone $(\mathrm{GnRH})$ and hypothalamic content of GnRH during the periovulatory period of the ewe Endocrinology 114 234-239

Delaleu B, Gautron JP, Antoine C, Locatelli A, Kordon C and Caraty A (1993) Mișe en évidence de la sécrétion d'un peptide apparenté à la (hydroxyprolineg)LHRH dans le sang porte hypothalamo hypophysaire de la brebis Annales d'endocrinologie 5419 (Supplement)
Domanski E, Chomicka LK, Ostrowska A, Gajewska A and Mateusiak K (1991) Release of luteinizing hormonereleasing hormone, beta-endorphin and noradrenaline by the nucleus infundibularis/median eminence during the periovulatory period in the sheep Neuroendocrinology $\mathbf{5 4}$ 151-158

Evans NP, Dahl GE and Karsch EJ (1993a) Estradiol induces qualitative and quantitative changes in the pattern of GnRH secretion during the pre-surge period in the ewe 75th meeting of the Endocine Society Abstract 1810

Evans NP, Dahl GE and Karsch FJ (1993b) Advent of the GnRH surge in the ewe is heralded by stereo-typical changes in the mode of GnRH secretion 23ra Amual Meeting of the Society for Neuroscierice Abstract 349.9

Gautron JP, Pattou E, Bauer K and Kordon C (1991) (Hydroxyproline) Luteinizing hormone-releasing hormone: a novel peptide in mammalian and frog hypothalamus Neurochemistry International 18 221-235

Gautron JP, Leblanc P, Bluet-Pajot MT. Pattou E. L'Heritier A, Mounier F, Ponce G, Audinot V, Rasolonjanahary R and Kordon C (1992) A second endogenous molecular form of mammalian hypothalamic luteinizing hormonereleasing hormone (LHRH), (hydroxyproline) LHRH, releases luteinizing hormone and follicle-stimulating hormone in vitro and in vivo Molecular and Cellular Eridocrinology 85 99-107

Goodman RL (1988) Neuroendocrine control of the ovine estrous cycle. In The Physiology of Reproduction pp 19291969 Eds E Knobil and JD Neill. Raven Press. New York

Irvine CHG and Alexander SL (1994) The dynamics of gonadotrophin-releasing hormone, LH and FSH secretion during the sponanteous ovulatory surge of the mare as revealed by intensive sampling of pituitary venous blood Journal of Endocrinology $140283-295$

Kaynard AH, Malpaux B, Robinson JE, Wayne NL and Karsch FJ (1988) Importance of pituitary and neural actions of estradiol in induction of the LH surge in the ewe Neuroendocrinology 48 296-303

Knobil E (1974) On the control of gonadotropin secretion in the rhesus monkey Recent Progress in Hormone Research 30 $1-25$

Knobil E, Plant TM, Wildt L, Belchetz PE and Marshall G (1980) Control of the rhesus monkey menstrual cycle: permissive role of hypothalamic gonadotropin-releasing homone Science $2071371-1373$

Lee WS, Smith MS and Hoffman GE (1992) cFos activity identi. fies recruitment of luteinizing hormone-releasing hormone neurones during the ascending phase of the proestrous luteinizing hormone surge Journal of Neuroendocrinology 4 161-166

Lehman MN and Karsch FJ (1993) Do GnRH, tyrosine hydroxylase and $\beta$-endorphin-immunoreactive neurons contain estrogert receptors? A double-label immunocytochemical study in the Suffolk ewe Endocrinology 133 887-895

Lehman MN, Ebling FJP, Moenter SM and Karsch FJ (1993) Distribution of estrogen-receptor immunoreactive cells in the sheep brain Endocrinology 133 876-886

Moenter SM, Caraty A and Karsch FJ (1990) The estradiolinduced surge of gonadotropin-releasing hormone in the ewe Endocrinology 127 1375-1384 
Moenter SM, Caraty A, Locatelli A and Karsch FJ (1991) Pattern of gonadotropin-releasing hormone $(\mathrm{GnRH})$ secretion leading up to ovulation in the ewe: existence of a precovulatory GnRH surge Endocrinology 129 1175-1182

Moenter SM, Brand RC and Karsch FJ (1992a) Dynarmics of gonadotropin-releasing hormone $(\mathrm{GnRH})$ secretion during the GnRH surge: insights into the mechanism of GnRH surge induction Endocrinology 130 2978-2984

Moenter SM, Brand RC. Midgley AR and Karsch FJ (I992b) Dynamics of gonadotropin-releasing hormone release during a pulse Endocrinology $130503-510$

Moenter SM, Karsch FJ and Lehman MN (1993) Fos expression during the estradiol-induced gonadotropinreleasing hormone ( $\mathrm{GnRH}$ ) surge of the ewe: induction in GnRH and other neurons Endocrinology 133 896-902

Nett TM, Crowder ME, Moss GE and Duello TM (1981) GnRH. receptor interaction. V. Down regulation of pituitary receptors for $\mathrm{GnRH}$ in ovariectomized ewes by infusion of homologous homone Biology of Reproduction $\mathbf{2 4}$ 1145-1155

Nishihara M, Sano A and Kimura F (1994) Cessation of the electrical activity of the gonadotropin-releasing hormone pulse generator during the steroid-induced surge of luteinizing hormone in the rat Neuroendocrinology 59 513-519

O'Byrne KT, Thalabard JC, Grosser PM, Wilson RC, Williams CL, Chen MD, Ladendorf D, Hotchikiss J and Knobil E (1991) Radiotelemetric monitoring of hypothalamic gonadotropin-releasing hormone pulse generator activity throughout the menstrual cycle of the thesus monkey Endocrinology 129 1207-1214

Padmanabhan V, Evans N, Caraty A and Karsch FJ (1994) Bioactive gonadotropin-releasing hormone (GnRH) is secreted throughout the estradiol-induced GnRH surge Biology of Reproduction 50 Supplement 1: Abstract 403

Pau KYF, Berria M, Hess DL and Spies HG (1993) Preovulatory gonadotropin-releasing hormone surge in ovary-intact thesus macaques Enidocrinology 133 1650-1656

Pelletier J and Signoret JP (1969) Contrôle de la décharge de LH dans le sang par la progestérone et le benzoate d'oestradiol chez la brebis castrèe Comptes Rendus-Academie des Sciences Panis Series D 269 2595-2598

Petersen SL, Cheuk C, Hartman D and Barraclough CA (1989) Medial preoptic microimplants of the antioestrogen.
Keoxifene, affect luteinizing hormone-releasing hormone mRNA levels, median eminence luteinizing hormone-releasing hormone concentrations and luteinizing hormone release in ovariectomized, oestrogen-treated rats Journal of Neuroendocrinology 1 279-283

Porkka-Heiskanen T, Urban J and Levine J (1993) Regional patterns of periovulatory LHRH gene expression in the rat 75th Anuual Meeting of the Endocine Sociefy Abstract 1800

Reeves JJ. Arimura A and Schally AV (1971) Changes in pituitary responsiveness to luteinizing hormone-releasing hormone (LH-RH) in anestrous ewes pretreated with estradiol benzoate Biology of Reproduction 4 88-92

Sarkar DK and Fink G (1979) Effects of gonadal steroids on output of luteinizing hormone releasing factor into pituitary stalk blood in the female rat Joumal of Endocrimology 80 303-313

Sarkar DD, Chiappa SA and Fink G (1976) Gonadotropinreleasing hormone surge in pro-oestrous rats Nature $\mathbf{2 6 4}$ $46 \mathrm{I}-463$

Schillo KK, Leshin LS, Kuehl D and Jackson GL (1985) Simultancous measurement of luteinizing hormone-releasing hormone and luteinizing hormone during estradiol-induced luteinizing hormone surges in the ovarjectomized ewe Biology of Reproduction $33 \quad 644-652$

Shivers BD, Harlan RE, Morrell II and Pfaff DW (1983) Absence of oestradiol concentration in cell nuclei of LHRHimmunoreactive neurones Nature 304 345-347

Silverman AJ, Witkin JW, Silverman RC and Gibson MJ (1990) Modulation of gonadotropin-releasing hormone neuronal activity as evidenced by uptake of fluorogold from the vasculature Synapse 6 154-160

Tanaka T, Mori Y and Hoshino K (1992) Hypothalarnic GnRH pulse generator activity during the estradiol-induced LH surge in ovariectomized goats Neuroendocrinology 56 64I-645

Thiery IC (1975) Etude de l'activité électrique des cellules de I'hypothalamus médio-basal chez la brebis à la suite d'injections d'oestrogènes Comptes Rendus-Acadentie des Sciences Paris Series D 281 1119-1122

Xia L, Van Vugt D, Alston EJ, Luckhaus J and Ferin M (1992) A surge of gonadotropin-releasing hormone accompanies the estradiol-induced gonadotropin surge in the rhesus monkey Endocrinology $1312812-2820$ 